\title{
General Approach to support Modelling of Data and Information Flows in Product Development
}

\author{
Jan Mehlstäubl ${ }^{1}$, Alexander Atzberger ${ }^{1}$, Kristin Paetzold ${ }^{1}$ \\ ${ }^{1}$ University of the Bundeswehr Munich, Germany \\ jan.mehlstaeubl@unibw.de, alexander.atzberger@unibw.de, \\ kristin.paetzold@unibw.de
}

\begin{abstract}
The efficient use and coordination of data and information is an important leaver for shorter development times and greater competitiveness of companies. In order to optimise data and information flows in product development, they must be captured and represented in a suitable form. Therefore engineering design processes must be abstracted and depicted in models with appropriate syntax. Due to high modelling effort, most process representations have a high degree of abstraction and show only sub-processes. For certain problems, such as the coordination and optimisation of data and information flows between two development departments and their individuals, it is necessary to split engineering design processes into individual working steps. Suitable methods are required to capture and model these data and information flows specifically for the individual modelling purpose.

In this paper, a methodical approach for detailed and purpose-oriented modelling of data and information flows in product development is introduced. Relevant domains are derived based on specific modelling purposes and depicted in a clear and understandable metamodel. This enables a detailed acquisition and optimisation of engineering design processes. The focus is on optimisation of data and information flows as well as supporting the designers and considering their requirements for process models. Moreover, options to acquire all necessary information to build process models are presented.

In this way, companies are able to record and analyse their data and information flows in a targeted and detailed manner. This increases transparency as well as process understanding and enables an optimisation of coordination between design departments. The approach is currently being evaluated in an industrial context.
\end{abstract}

Keywords: Engineering Design Processes; Process Modelling; Process Improvement; Data and Information Flows; Product Development 


\section{Introduction}

Companies have to introduce new products with more functionalities in shorter development times to ensure their competitiveness (Eversheim \& Schuh, 2005). For this reason, they are increasing the parallelisation of development activities, which leads to a multitude of data and information flows and challenges such as information overload, singular data usage and breaks in information flows (Lauer, 2010). Nevertheless, dependencies in data and information flows are ignored and offer therefore enormous potential for optimisation. The detailed consideration of processes require their recording with suitable models. However, most process models in industry are too general to provide support for daily work (Gericke \& Blessing, 2011) and only describe which development activities are to be carried out (Gericke \& Blessing, 2012). In order to coordinate data and information flows in product development efficiently and to support engineers in their daily work, specific models that provide information about dependencies between artefacts, roles and software tools are required. The effort for a detailed modelling and planning of design processes often exceeds a reasonable level (Negele, 1998). An alternative to providing a central model for all project participants is to provide sub-models for groups and individuals to support their individual purposes (Browning, 2010). The different model users have different requirements for the model content and level of detail. Appropriate methods are required for modelling of data and information flows with a high granularity. This results in the following research question:

- How can data and information flows be modelled in a detailed and targeted manner using a methodological procedure?

The aim of this work is to provide a procedure for detailed and purpose-oriented modelling of data and information flows in product development. This enables both, support of development activities by increased process transparency as well as optimisation by reducing information breaks and improving coordination between individuals and departments.

First, the paper provides a theoretical basis about engineering design processes and their properties, levels of detail and different users. Second, previous approaches that support modelling of engineering design processes are presented. Subsequently, the research approach of this work is outlined. Section 5 introduces the developed approach for detailed modelling of data and information flows in product development. Section 6 presents first results of the approach in an industrial context. Finally, the findings are discussed critically and a summary as well as an outlook for future research activities is given.

\section{Theoretical background}

\subsection{Engineering Design Processes}

Engineering design processes differ from normal business processes in manufacturing, controlling or administration. They are problem-solving processes in which knowledge about an object is generated (Kreimeyer, 2010). This results in uncertainties that make the development process less predictable than usual business processes.

Table 1 gives an overview of the characteristics of engineering design processes, which distinguish them from normal business processes and make detailed modelling and analysis more difficult. Due to these specific characteristics, approaches that support the management of well-known business processes are not applicable to engineering design processes (Roelofsen \& Lindemann, 2010). 
Table 1: Comparison of the characteristics of engineering design and business processes (Vajna, 2005)

\begin{tabular}{ll}
\hline \multicolumn{1}{c}{ Business Processes } & Engineering Design Processes \\
\hline - Processes are fixed, rigid, have to be & - Processes are dynamic, creative, \\
reproducible and checkable to 100\% & chaotic; many loops and go-tos \\
- Results have to be predictable & - Results are not always predictable \\
- Material, technologies, and tools are & Objects, concepts, ideas, designs, \\
physical (e.g., in manufacturing) and & $\begin{array}{l}\text { approaches, trials (and errors) are } \\
\text { virtual and not always precise }\end{array}$ \\
/ or completely described (e.g., in & - Possibility of disruptions is high \\
controlling) & because of imperfect definitions and \\
- Possibility of disruptions is low, & Thange requests \\
because objects and their respective & There is definitive need for dynamic \\
environments are described precisely & reaction capabilities \\
- No need for dynamic reaction &
\end{tabular}

\subsection{Hierarchical View on Engineering Design Processes}

Development processes can be depicted on different hierarchies. In this work, a distinction between three levels of detail is made. These are the generic procedural models, specific development processes and detailed workflows (see Figure 1).

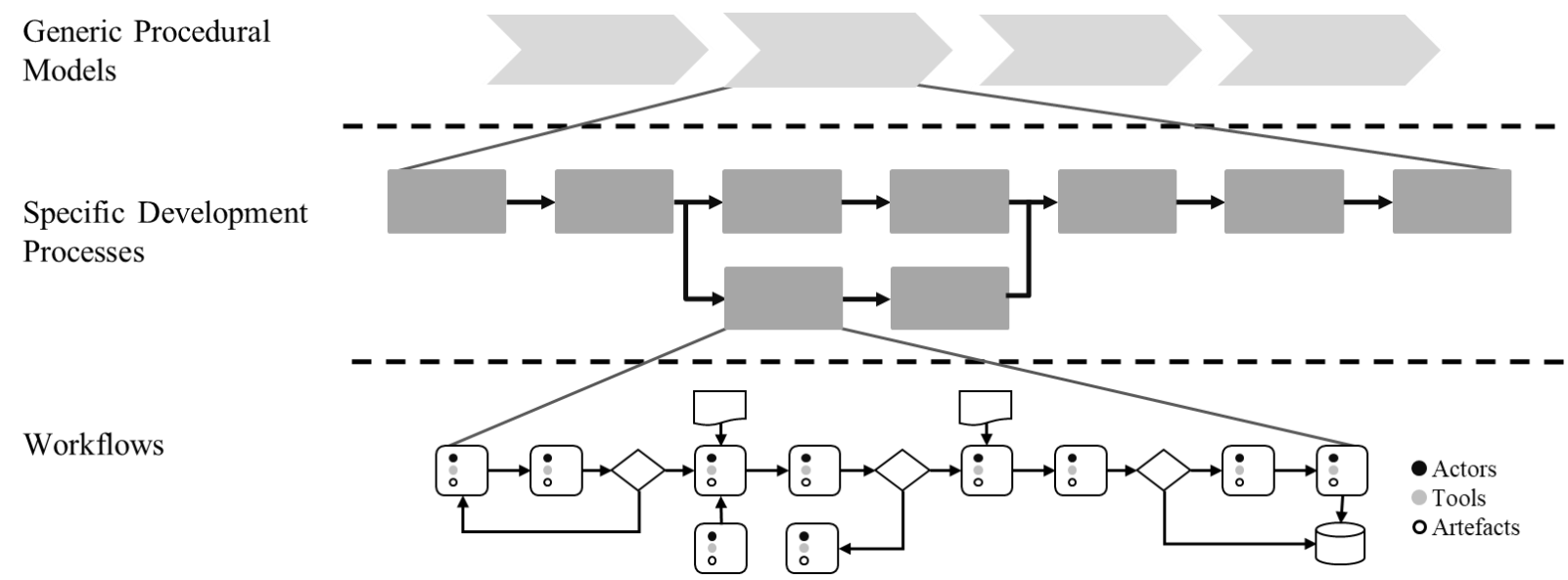

Figure 1: Hierarchical view on engineering design processes [adapted from Paetzold (2016)]

\section{Generic Procedural Models}

There are a number of procedural models and process plans for product development, which describe generic phases that are passed through in every development, regardless of the industry and the company under consideration. Pahl et al. (2005) distinguish in their procedural model for development and design between the four main phases planning and clarifying the task, conceiving, designing and elaborating. Another generic procedural model for product development is the $\mathrm{V}$ model of mechatronics (VDI 2206). The V model originates from software development and already defines suitable measures for verification in the specification phases. Further generic process models can be found in literature (see e.g. VDI 2221; Lindemann, 2009; Höhn \& Höppner, 2008). In order to support process planning in specific development situations, the generic procedural models are too abstract (Bürgel et al., 1996). Furthermore, the specific development context and constraints are not taken into account (Roelofsen, 2011). 


\section{Specific Development Processes}

In specific development processes, the generic phases of procedural models are further detailed and specified depending on the industry and company. They are standardised "to be" processes that must be tailored for planning a concrete development project. Usually they are used for project planning as well as meeting quality standards. They are usually limited to sub-process and provide only information about their chronological order. There is no specification of how the process should be carried out (Lauer, 2010).

\section{Workflows}

A workflow consists of individual working steps and their detailed description (Schöttner, 1999). This description provides information about execution-relevant details such as the generated data as well as responsible roles and tools used for execution. This means that the user is supported in his work directly by information on the procedure and the required inputs (Hastedt-Marckwardt, 1999). Such a detailed process description contributes significantly to the process transparency and reproducibility of decisions (Paetzold, 2016).

\subsection{User of Process Models in Engineering Design}

Process models are created in product development for different users. They pursue different goals that affect the required content and level of detail of the model. According to Browning (2010), the following users of process models can be distinguished:

- Project planners and schedulers: built process models to plan projects.

- Project managers and team leaders: use process models to support management decisions.

- Process owners: are responsible for documenting and maintaining processes and defining their interfaces.

- Engineers, designers, and other team members: use process models to complete their tasks and to understand the interfaces to other colleagues, departments or external companies.

Project planners and schedulers as well as project managers and team leaders are primarily interested in the sequence and duration of sub-processes. Therefore, they create and use specific development processes and tailor them for planning a concrete development project. Designers and process owners need a detail view on design processes and interfaces to understand and optimise them.

\section{State of the Art}

In literature, various approaches to support modelling of development processes can be found. Negele (1998) develops a methodology for holistic modelling of systems as well as development processes. In order to capture all relevant information, he defines the goal system, product system, process system and agent system. For the individual systems, relevant content is listed. The modelling is done with so-called development process modules. These can be used to describe inputs and outputs of process steps as well as their properties and transformation relationships. Bichlmaier (2000) deals in his work with methods for flexible design of integrated development processes. The focus is on detailing general procedural models to support planning at operational level. He also uses development process modules for modelling and adds additional fields with information about methods and tools that can be used for the process steps. In a process kit, the modules are collected as a template for modelling prospective design processes with a process modeller. The process modules can be changed and 
expanded as required. Freisleben (2001) presents a knowledge-based process model for the design and optimisation of product development processes. The model also shows methods and tools as well as company-specific IT tools to support the activities of general process modules. Roelofsen (2011) developed a procedure for the situation-specific planning of product development processes within the FORFLOW research association. The focus is on the product models that are used to analyse the specific situation. Based on the situation, process steps from the FORFLOW process model are proposed. She uses event-driven process chains for modelling. Browning (2018) presents the Integrative Process Modeling (IPM) approach for creating process models in product development. He assumes that complex processes behave like products and develops the IPM approach based on the V model. The approach can be used for various purposes, but is primarily intended to provide organisational support. Further work on process modelling is e.g. by Demers (2000), Redenius (2006), Kahl (2012), Voigtsberger (2005).

These approaches are limited to generic modules for process modelling and do not describe a procedure for a goal-oriented and company-specific process analysis. Moreover, they primarily deal with organisational planning and allocation of methods and tools to process modules. This results in process models with high level of abstraction that cannot be used for detailed analysis of data and information flows.

\section{Research Approach}

The results of this work were developed using a literature-based research design. First, the problem was identified and its relevance was examined. For this purpose, an intensive literature analysis on the management of engineering design processes as well as data and information flows in product development were carried out. Additionally, interviews with industrial partners were conducted. Subsequently, previous approaches with a similar aim were identified and their applicability in context of this investigation was estimated. Based on the literature analysis, a generic approach was developed to answer the research question and to fulfil the specified objectives. Therefore, the content of previous work was used and described in context of modelling data and information flows. The approach is currently being used and evaluated by an industrial company to confirm its applicability and success.

\section{Findings}

The following section presents the developed approach to support modelling of data and information flows. Fig. 2 gives an overview of the individual steps of the method. First, the different modelling purposes are identified that can be followed when dealing with data and information flows. Moreover, the scope of the modelling project must be limited in the beginning to reduce the effort to a minimum. Depending on the modelling purpose relevant views or domains must be determined. These domains and its relations must then be visualised in a clear and understandable metamodel. Finally, sources and procedures for acquire information to build the model are discussed.

\begin{tabular}{|c|c|c|c|}
\hline $\begin{array}{l}\text { 1. Specification of the } \\
\text { Modelling Purpose } \\
\text { - What is the goal of } \\
\text { modelling? } \\
\text { - What is the scope of } \\
\text { consideration? }\end{array}$ & $\begin{array}{l}\text { 2. Identification of } \\
\text { relevant Domains } \\
\text { - What content is required } \\
\text { to achieve the modelling } \\
\text { purpose? }\end{array}$ & $\begin{array}{l}\text { 3. Specification of a } \\
\text { Metamodel } \\
\text { - What is a suitable form } \\
\text { to represent the defined } \\
\text { domains and their } \\
\text { relations? }\end{array}$ & $\begin{array}{l}\text { 4. Acquisition of Data and } \\
\text { Information Flows } \\
\text { - What sources of } \\
\text { information are } \\
\text { available? } \\
\text { - Who is responsible for } \\
\text { modelling? }\end{array}$ \\
\hline
\end{tabular}

Figure 2: Overview of the approach 


\subsection{Specification of the Modelling Purpose}

In a modelling project, first, the goals and the context of consideration must be clarified. A process model that has been developed for a specific purpose can be unsuitable for another (Browning et al., 2006; Crowston, 2000). As already mentioned in chapter 2.3, the different users pursue different goals. A variety of modelling goals can be found in literature (see Bichlmaier, 2000; Browning, 2010; Fricke et al., 1998; Kreimeyer, 2010). Starting from these, the following modelling purposes for optimisation of data and information flows and support designers in their daily work were identified:

- Transparency: of the working steps to be carried out as well as upstream and downstream working steps and the associated data and information flows. (Bichlmaier, 2000; Fricke et al., 1998; Kreimeyer, 2010)

- Understanding: for the organisational dependencies, but also for the activities of colleagues from other departments. (Browning, 2010; Fricke et al., 1998)

- Coordination: of the exchange of data and information. (Bichlmaier, 2000; Fricke et al., 1998)

- Cooperation: establishing the exchange of information and coordination meetings between people and departments. (Bichlmaier, 2000; Browning, 2010)

- Standardisation: of the execution of working steps, documentation and exchange of data and information. (Browning, 2010)

- Support: by providing all necessary information to carry out working steps (input, output, methods, tools, etc.). (Bichlmaier, 2000; Browning, 2010)

In order to achieve the identified goals, the processes as well as their data and information flows must be modelled with a high level of detail. Thus, it is important to define the scope of modelling and system boundaries to limit the required effort. For this, the first and last considered process step or all relevant people and departments can be defined in advance.

\subsection{Identification of relevant Domains}

Attempting to digest all relevant information of a complex development project would lead to an information overload (Farhoomand \& Drury, 2002). Hence, it is important to determine all relevant aspects or domains (e.g. activities, people or artefacts) for problem solving. Depending on the modelling purpose, different domains and levels of detail must be considered (Browning et al., 2006; Eckert \& Stacey, 2010). For a systematic information acquisition, these must be specified first.

Figure 3 describes the dependencies between actual processes, process models, domains and attributes. Process models are abstractions of actual processes. They describe them with regard to a specific purpose and reduce them to relevant domains. Different process models of the same process can exist and represent it from different points of view. The individual models contain elements from different domains. For example, a flowchart is a process model and contains only elements from the activity domain. Depending on the modelling purpose, elements from additional domains such as roles responsible for the activities can be added. Attributes (e.g. name or duration) can characterise the elements of the domains more closely. 


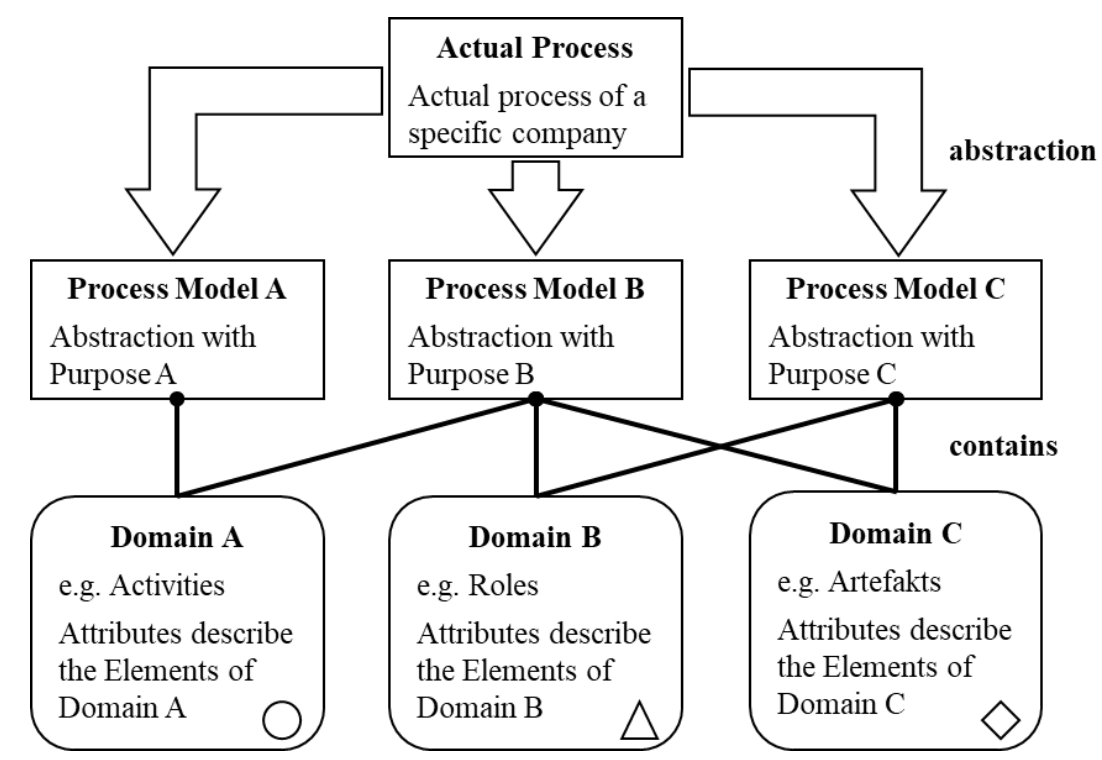

Figure 3: Dependencies between actual processes, process models and domains [adapted from Browning (2010)]

\subsection{Specification of a Metamodel}

A metamodel defines the syntax of a modelling language (Hesse \& Mayr, 2008). Metamodels enable the creation of models by instantiating their language elements (Chucholowski \& Lindemann, 2015). To model data and information flows, an own metamodel can be defined or an existing one can be used. Many overviews of modelling languages for processes can be found in literature (see Baumberger, 2007; Becker et al., 2012; Browning et al., 2006). However, most of them were designed to model a particular problem (see e.g. Gantt-Chart) or to cover many types of processes (see e.g. BPMN). This means that important language elements are either missing or too many language elements are provided. In order to model data and information flows, existing modelling languages can be extended or reduced. The aim is to capture all relevant information to fulfil the modelling purpose and to display them in a clear and understandable form. Figure 4 shows an example of a metamodel for recording data and information flows.

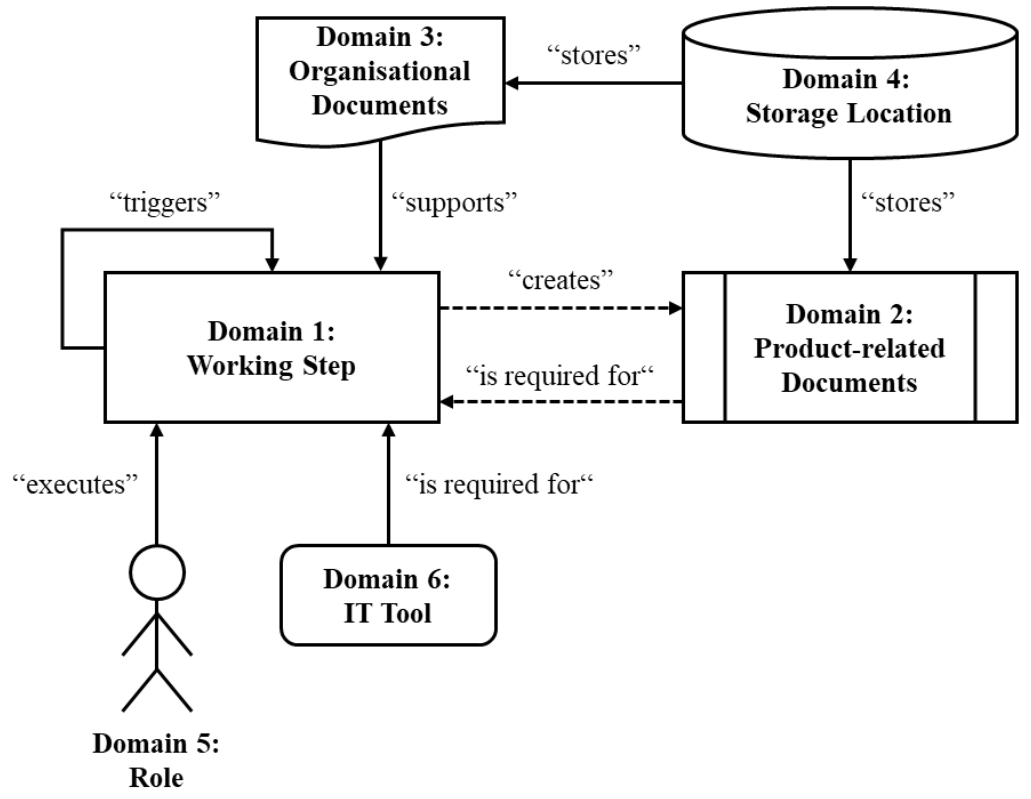

Figure 4: Exemplary metamodel to acquire data and information flows 
Only relevant domains and their connections were attempted for this specific modelling purpose. In order to carry out individual working steps (e.g. "create drawing" or "release drawing"), documents are required, which are filed in storage locations (e.g. databases, internal drives, etc.). In this work, a distinction is made between product-related documents that contain information about the product (e.g. CAD drawing, simulation reports, etc.) and organisational documents that offer no direct added value (e.g. design guidelines, checklists, etc.) (Porter, 2000). Furthermore, the responsible roles for the working steps and the IT tools with which the documents are generated are mapped in the metamodel.

\subsection{Acquisition of Data and Information Flows}

A top-down approach is recommended to acquire processes and associated data and information flows. Based on the generic procedural models and specific development processes, the detailed workflows are classified (see Figure 1). The higher hierarchical levels are only for classification and do not have to be fully modelled for the entire development. The top-down approach ensures that there is a link to processes with higher level of abstraction (Schönwald et al., 2018). For the classification internal documents of a company such as documented PDPs, quality and risk management documents can be used (Schönwald et al., 2018). It is important to involve designers who carry out the activities as well as possible when building process models (Browning et al., 2006). For this purpose, interviews, workshops or observations can be carried out. A further possibility is the decentralised modelling of the processes by designers themselves, since the effort for information procurement by a central department can quickly become too high (Negele, 1998).

\section{Use Case}

The approach is currently being applied and evaluated in an industrial context. In this section first findings and results of the evaluation are presented. Before applying the approach, the initial situation in the company was examined in more detail. The analysis focuses on the design as well as verification and validation phase. In these departments exist many different process models, especially for planning development projects or for quality certification. Above all, these are "to be" processes with a high degree of abstraction. During internal interviews, it became apparent that responsibilities for the generation and provision of information are not well defined. Moreover, documentation standards as well as storage locations are not specified for many intermediate development results.

In a previous project, attempts were made to record detailled processes in the area under consideration. In the created process diagrams, it can be seen that not all relevant domains have been recorded for this purpose. For example, the domain of the IT tools were not taken into account. On the other hand, no systematic approach was used, which means that the elements of the domains are not fully captured. For instance, the location of the CAD drawings was recorded, but not that of the simulation reports.

The aim of this use case is to improve the described weaknesses and to increase transparency about data and information flows, IT tools and storage locations using the developed approach. Furthermore, the provision of information between the departments is to be specified and the understanding of the designers about internal processes should be improved.

To meet the objectives, all relevant domains and their dependencies were defined and mapped in a metamodel (see Figure 4). In a first step, internal documents and previous process models were analysed to describe the data and information flows. The missing content was obtained through interviews with engineers. For reasons of secrecy, Figure 5 shows only a reduced and simplified section of the recorded processes. By using this methodical approach, all elements of the defined domains can be completely recorded and documented in a targeted manner. 
In this use case the process transparency is increased and standards e.g. for the storage locations of the documents or responsibilities can be defined. In addition, further subsequent analyses, such as an optimization of the IT system landscape or a parallelisation of working steps, are enabled.

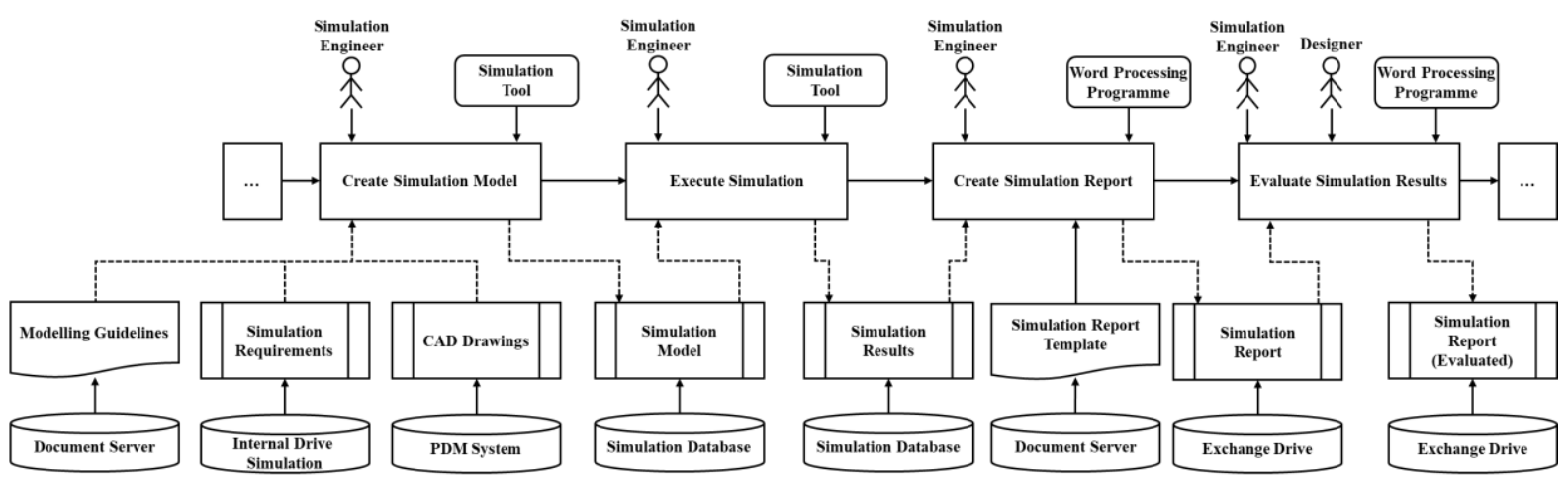

Figure 5: Exemplary application of the approach

\section{Discussion}

Previous approaches for modelling engineering design processes have a high level of abstraction and provide only standardised process modules. However, the analysis and optimisation of data and information flows require a detailed modelling of individual working steps and an enrichment of these with further information. Capturing all information in a single model leads to information overload. It is therefore necessary to enable companies to record their processes in a purpose-orientated manner.

The introduced approach answers the defined research question by providing a targeted procedure for detailed modelling of engineering design processes and its data and information flows. This increases process transparency and understanding of dependencies in an effective and efficient manner. The method also provides the basis for further process analysis and optimisation. Another benefit is the specific consideration of modelling purposes, domains and languages in context of data and information flows.

The developed approach is limited to the modelling of processes and does not provide any measures or options for further optimisations. The methodical process recording ensures the completeness of the elements of the defined domains. This directly increases transparency, understanding and offers support in the execution of work, but an improvement in coordination and cooperation as well as standardisation requires further analysis. Furthermore, dependencies between the modelling purposes, domains and languages of data and information flows are not specified in detail. Therefore, the required domains and an appropriate metamodel cannot be displayed automatically depending on a specific modelling purpose.

\section{Conclusion}

The holistic view on data and information flows offer high potentials for optimisation of product development processes. However, this requires detailed description of processes and resulting data and information flows. Approaches from literature have too abstract views on processes or describe only sequences of sub-processes. In this paper, an approach for detailed and targeted modelling of data and information flows was presented. In this, relevant domains are identified depending on the specific modelling purpose. Subsequently, a metamodel is created to visualise the specified domains and their dependencies. Finally, the systematic information acquisition is described. 
The developed approach is currently being evaluated in a company to validate its applicability and success. Prospective research activities will also include the mapping between modelling purposes, domains and metamodels in context of data and information flows. As a result, depending on the modelling purpose, the required domains and their options for visualisation can be provided automatically in a metamodel. Another area for future research is the extension of the approach by measures for further analysis and optimisation in order to improve coordination and cooperation as well as standardisation of data and information exchange.

\section{References}

Baumberger, G. C. (2007). Methoden zur kundenspezifischen Produktdefinition bei individualisierten Produkten.

Becker, J., Probandt, W., \& Vering, O. (2012). Grundsätze ordnungsmäßiger Modellierung. Springer Berlin Heidelberg.

Bichlmaier, C. (2000). Methoden zur flexiblen Gestaltung von integrierten Entwicklungsprozessen. Herbert Utz Verlag.

Browning, T. R. (2010). On the alignment of the purposes and views of process models in project management. Journal of Operations Management, 28(4), 316-332.

Browning, T. R. (2018). Building models of product development processes: An integrative approach to managing organizational knowledge. Systems Engineering, 21(1), 70-87.

Browning, T. R., Fricke, E., \& Negele, H. (2006). Key concepts in modeling product development processes. Systems Engineering, 9(2), 104-128.

Bürgel, H. D., Haller, C., \& Binder, M. (1996). F-\&-E-Management. Vahlen.

Chucholowski, N., \& Lindemann, U. (2015). An initial metamodel to evaluate potentials for graphbased analyses of product development projects. Modeling and Managing Complex Systems - Proceedings of the 17th International DSM Conference, 77-88.

Crowston, K. (2000). Process as theory in information systems research. In Organizational and social perspectives on information technology (pp. 149-164). Springer.

Demers, M. T. (2000). Methoden zur dynamischen Planung und Steuerung von Produktentwicklungsprozessen. Technische Universität München.

Eckert, C. M., \& Stacey, M. K. (2010). What is a Process Model? Reflections on the Epistemology of Design Process Models. Modelling and Management of Engineering Processes, 3-14.

Eversheim, W., \& Schuh, G. (2005). Integrierte Produkt- und Prozessgestaltung. VDI. Springer.

Farhoomand, A. F., \& Drury, D. H. (2002). Managerial information overload. Communications of the ACM.

Freisleben, D. (2001). Gestaltung und Optimierung von Produktentwicklungsprozessen mit einem wissensbasierten Vorgehensmodell. Otto-von-Guericke-Univ., Lehrstuhl für Maschinenbauinformatik.

Fricke, E., Negele, H., Schrepfer, L., Dick, A., Gebhard, B., \& Hartlein, N. (1998). Modeling of concurrent engineering processes for integrated systems development. In 17th DASC. AIAA/IEEE/SAE. Digital Avionics Systems Conference. Proceedings (B13/1-B13/8). IEEE.

Gericke, K., \& Blessing, L. (2011). Comparisons of design methodologies and process models across disciplines: A literature review. ICED 11, 393-404.

Gericke, K., \& Blessing, L. (2012). An analysis of design process models across disciplines. Proceedings of International Design Conference, DESIGN, DS 70, 171-180.

Hastedt-Marckwardt, C. (1999). Workflow-Management-Systeme Ein Beitrag der IT zur Geschäftsprozeß-Orientierung \&-Optimierung-Grundlagen, Standards und Trends-. Informatik-Spektrum, 99-109. 
Hesse, W., \& Mayr, H. C. (2008). Modellierung in der Softwaretechnik: eine Bestandsaufnahme. Informatik-Spektrum, 31(5), 377-393.

Höhn, R., \& Höppner, S. (2008). Das V-Modell XT: Grundlagen, Methodik und Anwendungen. Springer-Verlag.

Kahl, S. (2012). Rahmenwerk für einen selbstoptimierenden Entwicklungsprozess fortschrittlicher mechatronischer Systeme.

Kreimeyer, M. (2010). A Structural Measurement System for Engineering Design Processes.

Lauer, W. (2010). Integrative Dokumenten- und Prozessbeschreibung in dynamischen Produktentwicklungsprozessen. Lehrstuhl Für Produktentwicklung.

Lindemann, U. (2009). Methodische Entwicklung technischer Produkte.

Negele, H. (1998). Systematische Methodik zur ganzheitlichen Modellierung am Beispiel der integrierten Produktentwicklung.

Paetzold, K. (2016). Workflowunterstützung in der Produktentwicklung, 1049-1068.

Pahl, G., Beitz, W., Feldhusen, J., \& Grote, K.-H. (2005). Konstruktionslehre: Grundlagen erfolgreicher Produktentwicklung Methoden und Anwendung (6. Aufl.). SpringerLehrbuch. Springer.

Porter, M. E. (2000). Wettbewerbsvorteile: Spitzenleistungen erreichen und behaupten (6th ed.). Campus-Verl.

Redenius, A. (2006). Verfahren zur Planung von Entwicklungsprozessen für fortgeschrittene mechatronische Systeme. Heinz-Nixdorf-Inst.

Roelofsen, J. (2011). Situationsspezifische Planung von Produktentwicklungsprozessen.

Roelofsen, J., \& Lindemann, U. (2010). An Approach Towards Planning Development Processes According to the Design Situation. In P. Heisig, P. J. Clarkson, \& S. Vajna (Eds.), Modelling and Management of Engineering Processes (pp. 41-52). Springer.

Schönwald, J., Fleskes, J., Forsteneichner, C., \& Paetzold, K. (2018). A method for a detailed analysis of verification and validation processes in product development. Design 2018, 1313-1324.

Schöttner, J. (1999). Produktdatenmanagement in der Fertigungsindustrie: Prinzip, Konzepte, Strategien. Hanser.

Vajna, S. (2005). Workflow for design. In Design process improvement (pp. 366-385). Springer.

VDI 2206 (2004). Entwicklungsmethodik für mechatronische Systeme. VDI Verlag.

VDI 2221 (1993). Methodik zum Entwicklen und Konstruieren technischer Systeme und Produkte. VDI Verlag.

Voigtsberger, J. (Ed.). (2005). Berichte aus dem Produktionstechnischen Zentrum Berlin. Adaptive Modellierung und Simulation von Produktentwicklungsprozessen. Zugl.: Berlin, Techn. Univ., Diss. 